\title{
THE IMPACT OF RUBBER CRUMB ON THE MECHANICAL AND CHEMICAL PROPERTIES OF CONCRETE
}

\author{
Joseph Olawale AKINYELE, Ramadhan Wanjala SALIM, Williams Kehinde KUPOLATI \\ Department of Civil Engineering, Tshwane University of Technology, Pretoria, South Africa
}

Received 08 December 2015; accepted 05 February 2016

\begin{abstract}
Various works have been carried out on both the physical and mechanical properties of rubberized concrete in previous research. But the chemical composition of rubberized concrete has not been fully investigated. The scanning electron microscopy (SEM) and energy-dispersive $\mathrm{x}$-ray spectrum (EDX) analysis were used to determine the element composition and the peak intensity of chemical elements in the waste rubber concrete. The SEM and EDX analysis results showed that, ferrous iron, oxygen, calcium, and silicon were the dominant elements, and these elements reduced as more waste rubber were added to the concrete. Carbon and sulphur elements increased as rubber crumbs were added to the rubberized concrete. The work concluded that the presence of rubber crumb in the concrete samples contributed to both mechanical and chemical changes in the property of rubberized concrete.
\end{abstract}

Keywords: waste rubber, rubberized concrete, SEM analysis, EDX analysis, rubber crumb.

\section{Introduction}

Rubberized concrete is a product of the replacement of some concrete raw materials with rubber, many work have been carried out in the area of rubberized concrete where, fine and coarse aggregates were fully or partially replaced by rubber waste in concrete. Most of these researchers have focused majorly on the effect of rubber or sometimes plastic waste on the physical and mechanical properties of concrete, the aim of these past researched works cannot be disputed because it is believed that the most important characteristic of concrete is the mechanical properties.

Gupta et al. (2015) considered the effect of replacing fine aggregates by waste rubber fibers and the impact resistance of concrete, the work also considered silica fume as replacement of cement. Six replacement levels of rubber fiber $(0 \%, 5 \%, 10 \%, 15 \%, 20 \%$ and $25 \%$ ) and three replacement levels of silica fume $(0 \%, 5 \%$ and $10 \%)$ were considered for three different water cement ratios. Impact tests on concrete were conducted by three different techniques; drop weight test, flexural loading test and rebound test. The study concluded that waste rubber fiber can be conveniently used as a material to improve the ductility and impact resistance of concrete, and also demonstrates that the silica fume improved the impact resistance and reduces the ductility of rubberized concrete.

Duarte et al. (2015) carried out a numerical procedure to characterize the mechanical behaviour of rubberized concrete, the splitting tensile strength test was particularly considered. The research used MATLAB image processing to obtain the model geometry and the distribution of rubber particles within the concrete matrix. Also, the Extended Finite Element Method (XFEM) adopting the ABAQUS software was used to simulate the inelastic behaviour of the concrete matrix, thus allowing the nucleation and development of cracks, as well as the damage evolution and ultimate strength of the rubberized concrete specimen crosssection. The results showed that rubberized concrete 
has both lower strength and stiffness but higher ductility than normal concrete.

Güneyisi et al. (2004) also carried out studies on the mechanical properties of rubberized concretes with and without silica fume. Crumb rubber and shredded rubber, were used as fine and coarse aggregate respectively, partially replacing the aggregate with rubber at varying contents from $2.5 \%$ to $50 \%$ by volume. Silica fume was used to partially substitute cement at varying percentage of $5-20 \%$ in the concrete. Compressive, splitting tensile strengths and static modulus of elasticity test were carried out. The work observed that there was a general reduction in strength of concrete as revealed by previous work; the conclusion of the research was that the addition of silica fume into the matrix improved the strength of the rubberized concretes.

Topçu (1995) studied the physical and mechanical properties of rubberized concrete with an initial compressive strength of $20 \mathrm{~N} / \mathrm{mm}^{2}$, aggregate in concrete were replaced by $15 \%, 30 \%$ and $45 \%$ rubber. The study also revealed general decrease in the compressive strength of concrete, meanwhile the plastic energy capacity of the normal concrete was improved by the addition of rubber, due to the high plastic energy capacities, the concrete showed high strain especially under impact load. Zhang et al. (2014) combined cement matrix and waste rubber in concrete, the rubber particles were treated with acrylic acid (ACA) and polyethylene glycol (PEG). The X-Ray photoelectron spectroscopy (XPS) and surface contact angle were used to characterize the hydrophilicity and surface functional group of rubber particles. The experimental results showed that the contact angle between rubber particle surface and water diminish when rubber particle was modified.

Karakurt (2015) investigated the microstructure properties of waste tire rubber composites; his results confirmed that adhesion between rubber particles and cement matrix is significant for the final product properties. He also propounded that the physical and mechanical properties of asphalt composites can be improved with the addition of waste rubber into the mixture. Zheng et al. (2008) studied a simply supported slab beam using a free vibration method to determine the damping ration in small warp and the effect of rubber particles in rubberized concrete. The work observed improved damping ration of rubberized concrete when compared to those of normal concrete, the research concluded by providing helpful information for a better understanding of dynamic characteristics of rubberized concrete.
Ganjian et al. (2009) incorporated 5\%, 7.5\% and $10 \%$ of discarded tyre rubber as aggregate and cement replacements in concrete, test such as compressive strength, tensile strength, flexural strength and modulus of elasticity were carried out. The results showed that with up to $5 \%$ replacement in each set, no major changes on concrete properties occurred, nevertheless, with further increase in replacement ratios some changes were observed. Toutanji (1996) and Eldin and Senouci (1993) reported in their different work that the addition of rubber to normal concrete could increase the deformability or ductility of rubberized concrete members. The rubberized concrete could be used in places where deformability or toughness is important than strength, especially in structural members like bridge barriers and road foundation.

Most of the research work listed above focused more on the physical and mechanical properties of rubberized concrete. The major aim of this work is to look in to both the mechanical and most especially the chemical properties of rubberized concrete and investigate the effects of detected chemical elements on the concrete.

\section{Experimental procedures}

\subsection{Concrete mix design}

The rubber crumb used in the research work was obtained from a recycling plant, TOSAS in Wadeville, South Africa. The rubber crumb was used to replace fine aggregate in concrete by $0,4,8,12$ and $16 \%$, and the concrete samples were designated as $\mathrm{C}_{0}, \mathrm{C}_{4}, \mathrm{C}_{8}$, $\mathrm{C}_{12}$ and $\mathrm{C}_{16}$ respectively. The water cement ratio used in the experiment was 0.5 ; the concrete mix design was 1:2:3. The cement used was ordinary Portland cement $(\mathrm{CEM} 132.5 \mathrm{~N})$, river sand was used as the fine aggregate and crushed granite as the coarse aggregate. Compressive and tensile strength tests were carried out on the hardened concrete. The cube size used for the compressive strength test was $100 \times 100 \times 100 \mathrm{~mm}$ size while for the tensile strength test; the cylinder size was $150 \times 300 \mathrm{~mm}$.

\subsection{Compressive strength}

The compressive strength for all the concrete cubes was determined in accordance with South African standard, SANS 5863 (2006) and BS 12390 parts 3 (2009). Each concrete was prepared in accordance with the percentage mixes been investigated in this work. Three 
samples for each curing age and for the percentage replacement were replicated; over 70 cubes were cast in the experiment. The compressive strength of each cube was determined from kingtest compressive testing machine of $2000 \mathrm{kN}$ capacity at a load rate of $180 \mathrm{kN} /$ $\mathrm{min}$. All the samples were tested to failure by crushing and the maximum load recorded, the maximum load divided by the area of each cube gave the compressive strength of the samples. The average compressive strength for each specimen was taken from three results as the resultant strength. Tests were carried out at $7,14,21,28$ and 70 days for all the concrete samples.

\subsection{Split tensile strength}

Testing for split tensile strength of concrete was done according to ASTM C 496-96 (ASTM C496/ C496M-11: 2004). The test was conducted on the same compressive testing machine, a total of 30 cylinders were used for the test. The concrete cylinders were placed horizontally between the loading surfaces of compression testing machine and the load was applied at the rate of $100 \mathrm{kN} /$ minute until the failure of the cylinder, during the test the flat plates of the machine were not allowed to rotate in a plane perpendicular to the axis of cylinder, the splitting tensile test equation is shown below.

$$
\frac{2 P}{\pi L D} \ldots 1
$$

where: $\mathrm{P}$ - load at failure, $\mathrm{L}$ - length of the cylinder and $\mathrm{D}$ - diameter of the cylinder.

\subsection{SEM and EDX analysis}

Image analysis of specimens obtained from small fragments of concrete samples which was used for the compressive strength analyses provided samples suitable for this investigation. The concrete samples were cut from the cubes after the compressive strength test into $5 \mathrm{~mm}$ thickness and about $15 \mathrm{~mm}$ length; the fractured small samples were mounted on the SEM stubs. Images from unpolished surfaces of these concrete fragments allow evidence of chemical composition of the rubberized concrete. Scanning electron microscopy (SEM)-based images came from scanning electron microscopy JEOL JSM7600F, located in the Chemical and Metallurgical Engineering Laboratory of the Tshwane University of Technology, Pretoria. After the concrete samples were prepared for SEM studies, images were extracted from each and more than seven iterations were performed on each concrete samples.

\section{Results and discussion}

\subsection{Compressive strength test result}

The compressive strength test results are showed in Figure 1, the general trend is that the compressive strength reduces as the percentage of rubber crumb increases in the concrete mix; this observation is in agreement with previous research work on rubberized concrete. The 70 days ultimate strength for Control specimen $\left(\mathrm{C}_{0}\right)$ was more than that of $\mathrm{C}_{4}$ specimens by $4.94 \mathrm{~N} / \mathrm{mm}^{2}$, while $\mathrm{C}_{4}$ sample was higher than $\mathrm{C}_{8}$ by $10.33 \mathrm{~N} / \mathrm{mm}^{2}$, however $\mathrm{C}_{8}$ was higher than $\mathrm{C}_{12}$ by $9.54 \mathrm{~N} / \mathrm{mm}^{2}$ while $\mathrm{C}_{16}$ was $3.97 \mathrm{~N} / \mathrm{mm}^{2}$ lower than $\mathrm{C}_{12}$. It was observed from the graph that there was gradual improvement in the compressive strength of all the members from the first day to the $28^{\text {th }}$ day, the control sample then resulted into linear increase up to 70 days, the 28 days strength was $51.88 \mathrm{~N} / \mathrm{mm}^{2}$ while the $70^{\text {th }}$ day test was $52.08 \mathrm{~N} / \mathrm{mm}^{2}$ a marginal difference of $0.2 \mathrm{~N} / \mathrm{mm}^{2}$.

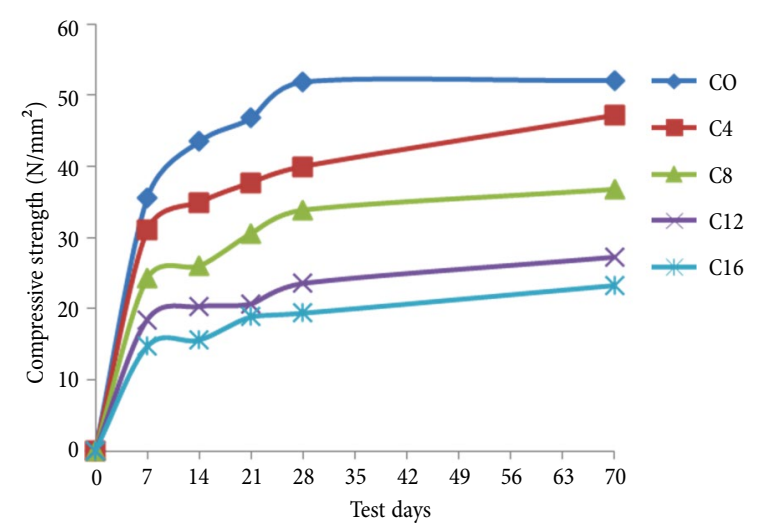

Fig. 1. Compressive strength test results

But it was not the same case for all the samples that contained rubber crumb, the difference between the 28 and 70 days strength for $\mathrm{C}_{4}$ sample was $7.19 \mathrm{~N} / \mathrm{mm}^{2}$, and that of $\mathrm{C}_{8}$ was $2.92 \mathrm{~N} / \mathrm{mm}^{2}$, specimen $\mathrm{C}_{12}$ has a difference of $3.70 \mathrm{~N} / \mathrm{mm}^{2}$ while that of $\mathrm{C}_{16}$ was $3.9 \mathrm{~N} /$ $\mathrm{mm}^{2}$. These results imply that concrete samples with rubber crumb in it have a higher rate of strength increments than the control sample after the 28 days test.

\subsection{Tensile test}

The tensile test result for 14 and 28 days for all the samples are showed in Figure 2. It can be observed that the tensile strength of the samples reduces as the rubber crumb added to the samples increases. The tensile strength for the control $\mathrm{C}_{0}$ is 2.76 and $3.11 \mathrm{~N} /$ $\mathrm{mm}^{2}$ for the 14 and 28 days test respectively. The ten- 


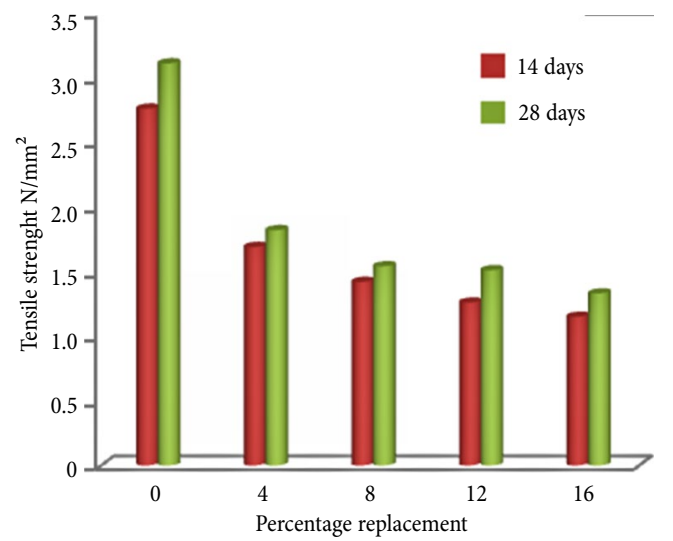

Fig. 2. Tensile strength test result

sile strength reduced by 39 and $41 \%$ at 14 and 28 days respectively for the $\mathrm{C}_{4}$ sample. This trend continued for the entire concrete sample until when $\mathrm{C}_{16}$ gave1.15 and $1.33 \mathrm{~N} / \mathrm{mm}^{2}$ at 14 and 28 days respectively. The reduction in tensile strength can be attributed to the weak interfacial adhesive force between the cement paste and the elongated surface of the rubber crumb.

\subsection{SEM analysis results}

It is a well known fact that concrete consists of three major materials of cement, fine aggregate and coarse aggregate, of these three major materials of concrete, it is only cement that is not a naturally occurring material and it functions as the binder in concrete. Cement is prepared by heating limestone (a source of calcium) with clay and grinding this product with a source of sulfate. Cement consists of a mixture of oxides of calcium, silicon and aluminium. The proportion of $\mathrm{CaO}$, $\mathrm{SiO}_{2}, \mathrm{Al}_{2} \mathrm{O}_{3}, \mathrm{Fe}_{2} \mathrm{O}_{3}, \mathrm{MgO}$ and $\mathrm{SO}_{3}$ in cement are $63 \%$, $21.9 \%, 6.9 \%, 3 \%, 2.5 \%$ and $1.7 \%$ respectively. All these chemical content consist of deferent elements that react together to give the different oxides, these elements are present either by atomic weight or by mass.

Table 1 showed the element composition of all the concrete samples obtained from the $\mathrm{x}$-ray micro analysis, it can be observed from the table that the amount of Oxygen $(\mathrm{O})$ is more than any other element in all the samples; this is because it is the dominant element in concrete, both it mass and atomic percentage reduces as the amount of rubber crumb increases in the concrete, the magnesium $(\mathrm{Mg})$ also reduces in mass and atomic weight as rubber crumb increases, the same condition applied to silicon $(\mathrm{Si})$, with the exception of sample $\mathrm{C}_{12}$ which has higher proportion of silicon in it. Aluminium (Al) also reduces as more rubber crumbed was added to concrete with sample $\mathrm{C}_{12}$ changing the trend. The same condition applied to the ferrous iron $(\mathrm{Fe})$ element. Sample $\mathrm{C}_{8}$ did not have any trace of Phosphorous (P), but the element reduced in other concrete samples as rubber crumbs content increases in the concrete, with the exception of sample $\mathrm{C}_{12}$ that has the same amount of element as the control sample $\mathrm{C}_{0}$. For calcium (Ca) which reacts with oxygen to form the major oxide in concrete, the element reduces in the samples as the amount of rubber crumb increases with the exception of sample $\mathrm{C}_{4}$ which has the highest percentage of calcium in it. $\mathrm{C}_{12}$ is the only sample that contains potassium $(\mathrm{K})$, while carbon $(\mathrm{C})$ and sulphur (S) increases as the percentage of rubber crumb increased in all the samples, it is believed that the majority of these two elements are from the rubber crumb, since tire rubber contains a very high percentage of carbon black and sulphur in it. The general trend from the $\mathrm{x}$-ray analysis showed that the presence

Table 1. Components of concrete samples

\begin{tabular}{|c|c|c|c|c|c|c|c|c|c|c|}
\hline Element & \multicolumn{2}{|c|}{ Sample $\mathrm{C}_{0}$} & \multicolumn{2}{|c|}{ Sample $\mathrm{C}_{4}$} & \multicolumn{2}{c|}{ Sample $\mathrm{C}_{8}$} & \multicolumn{2}{c|}{ Sample $\mathrm{C}_{12}$} & \multicolumn{2}{c|}{ Sample $\mathrm{C}_{16}$} \\
\hline & Weight \% & Atomic $\%$ & Weight \% & Atomic \% & Weight \% & Atomic \% & Weight \% & Atomic \% & Weight \% & Atomic \% \\
\hline $\mathrm{C}$ & 4.91 & 8.31 & 8.35 & 13.85 & 6.74 & 11.05 & 8.39 & 14.12 & 17.80 & 27.22 \\
\hline $\mathrm{O}_{2}$ & 52.92 & 67.19 & 52.44 & 65.28 & 55.49 & 68.32 & 47.49 & 60.03 & 48.11 & 55.24 \\
\hline $\mathrm{Mg}$ & 2.73 & 2.28 & 0.41 & 0.34 & 0.72 & 0.58 & 2.31 & 1.92 & 0.47 & 0.35 \\
\hline $\mathrm{Al}$ & 2.94 & 2.21 & 1.90 & 1.40 & 1.98 & 1.45 & 3.75 & 2.81 & 2.67 & 1.82 \\
\hline $\mathrm{Si}$ & 8.80 & 6.36 & 5.68 & 4.02 & 8.40 & 5.89 & 11.32 & 8.15 & 7.20 & 4.71 \\
\hline $\mathrm{P}$ & 0.90 & 0.59 & 0.35 & 0.23 & - & - & 0.91 & 0.59 & 0.60 & 0.36 \\
\hline $\mathrm{S}$ & 0.92 & 0.58 & 1.16 & 0.72 & 1.38 & 0.85 & 1.19 & 0.75 & 1.50 & 0.86 \\
\hline $\mathrm{Ca}$ & 21.42 & 10.85 & 25.38 & 12.61 & 21.19 & 10.41 & 17.14 & 8.65 & 17.99 & 8.25 \\
\hline $\mathrm{Fe}$ & 4.46 & 1.62 & 4.33 & 1.54 & 4.11 & 1.45 & 5.81 & 2.10 & 3.65 & 1.20 \\
\hline $\mathrm{K}$ & - & - & - & - & - & - & 1.70 & 0.88 & - & - \\
\hline
\end{tabular}


of rubber crumb in the concrete samples has some serious effect on the chemical composition of concrete by altering the amount of different elements present in the concrete samples. Although ordinary rubber may look chemically inert at room temperature, but the result obtained from this work showed that there are some level of chemical reactions within the concrete matrix due to the effect of rubber crumb, especially during the hydration period. The high sulphur and carbon present in the rubberized concrete acts as impurities during the hydration process and this led to the poor reactions in the chemical process and the eventual reduction in strength of concrete.

\subsection{EDX analysis}

The EDX analysis will basically help to determine the peak positions of element in a material and this position are specific to a particular element. The intensity (height) of each element is proportional to its relative abundance in the material. This can occur when X-radiation is produced by the time a specimen is barraged by high-energy electrons. The rays of electrons eject inner-shell electrons that are then substituted by outershell electrons. This substitution results in emission of an $\mathrm{x}$-ray characteristic for that element. The $\mathrm{x}$-ray energy level is exhibited as the number of counts at each energy interval and emerges as peaks on a continuous background and referred to as an energy-dispersive $\mathrm{x}$ ray spectrum (EDX) (FHWA-04-150 (FHWA 2006)).

It can be observed from Figures 3-7, that the peak positions of each element were determined from the concrete samples used in this work. The spectrum from concrete samples, exhibits mineral's characteristic composition with oxygen, ferrous iron and calcium been the dominant elements. The unit on the horizontal axis is in kiloelectronvolts (keV). From Figure 3, ferrous iron $(\mathrm{Fe})$, calcium $(\mathrm{Ca})$ and oxygen $(\mathrm{O})$ exhibited the highest intensity with Fe at the peak, and this took place at $0.5 \mathrm{keV}$, silicon ( $\mathrm{Si})$, aluminium $(\mathrm{Al})$ has the next higher intensity at $1.8 \mathrm{keV}$, there was another element of calcium manifested at $3.8 \mathrm{keV}$. Carbon was noticeable at $0.3 \mathrm{keV}$, magnesium was between 1.3 and $1.5 \mathrm{keV}$, there was also a trace of ferrous iron element at $6 \mathrm{keV}$ but the intensity was very low. The dominance of $\mathrm{Fe}, \mathrm{Ca}$, and $\mathrm{O}$ was also observed in Figures 4 to 7 , and all the peak intensity took place at $0.5 \mathrm{keV}$ as was the case of the control sample, but in Figure 4, another trace of calcium has the next higher peak at $3.8 \mathrm{keV}$ than silicon and aluminium at $1.8 \mathrm{keV}$, other elements

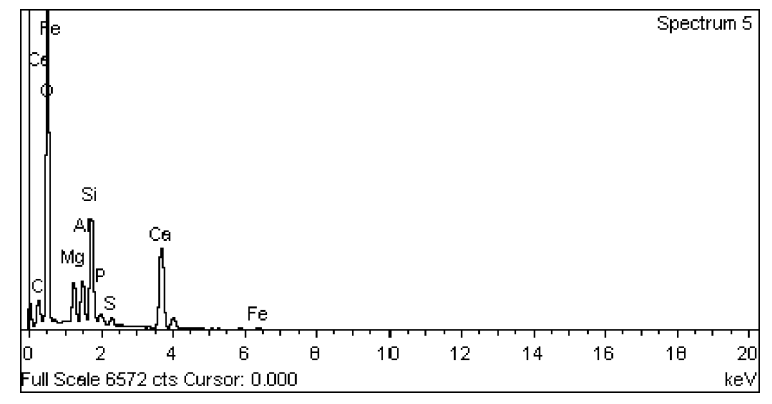

Fig. 3. Element peaks in sample $\mathrm{C}_{0}$

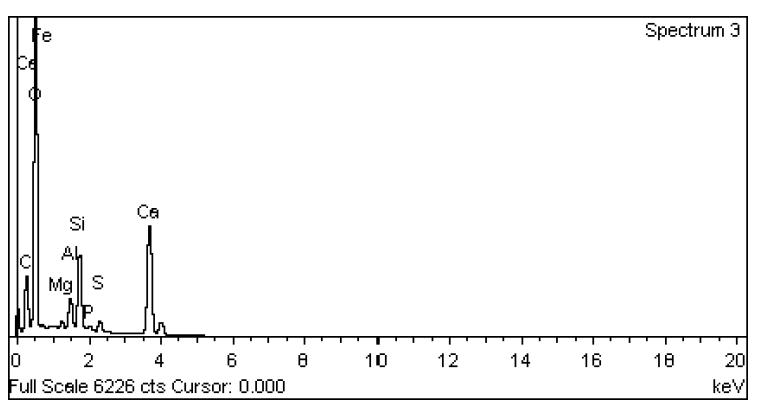

Fig. 4. Element peaks in sample $\mathrm{C}_{4}$

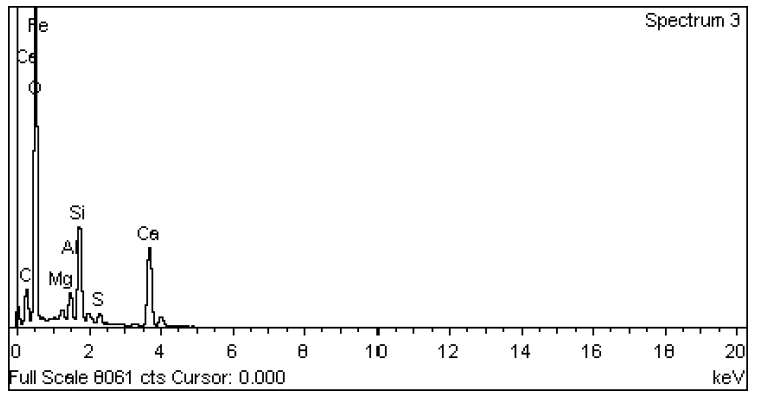

Fig. 5. Element peaks in sample $\mathrm{C}_{8}$

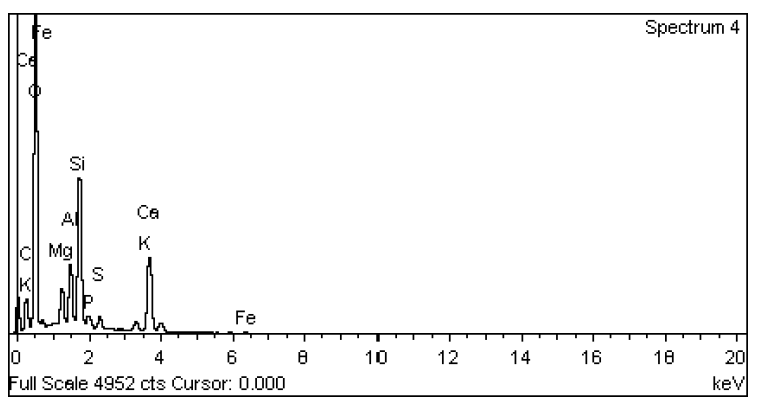

Fig. 6. Element peaks in sample $\mathrm{C}_{12}$

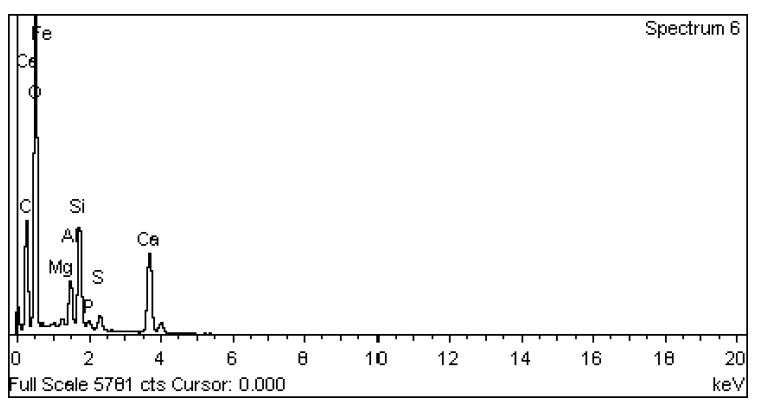

Fig. 7. Elements peak in sample $C_{16}$ 
such as magnesium, phosphorus, can be found with lower intensity, sulphur has the lowest peak in all the samples but at $2.4 \mathrm{keV}$. Interestingly, the element potassium (K) was manifested in sample $\mathrm{C}_{12}$ (Fig. 6) only with a very good intensity, it was recessive at $0.4 \mathrm{keV}$ but well manifested at $3.8 \mathrm{keV}$ along with the excess calcium element. The major advantage of the EDX analysis is for: (a) spectrum analysis for quantitative and qualitative chemical analyses. (b) Plotting of relative concentration of selected elements along a line using scan analysis. (c) Spatial distribution and relative concentrations of elements using x-ray imaging (XR) and (d) Aid in phase identification through its chemical signature (FHWA-04-150 (FHWA 2006)).

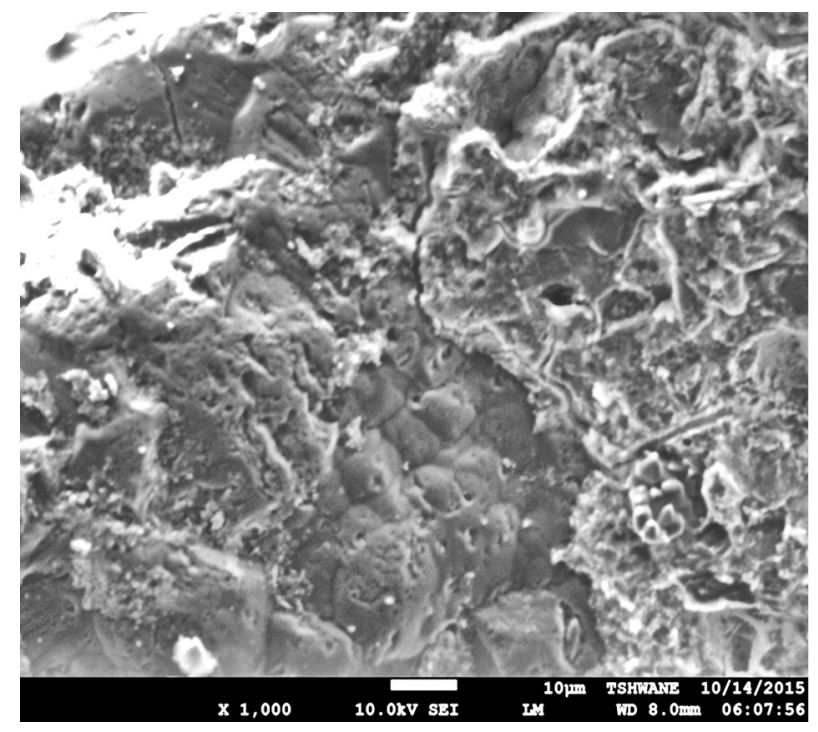

Fig.8. Sample $\mathrm{C}_{0}$

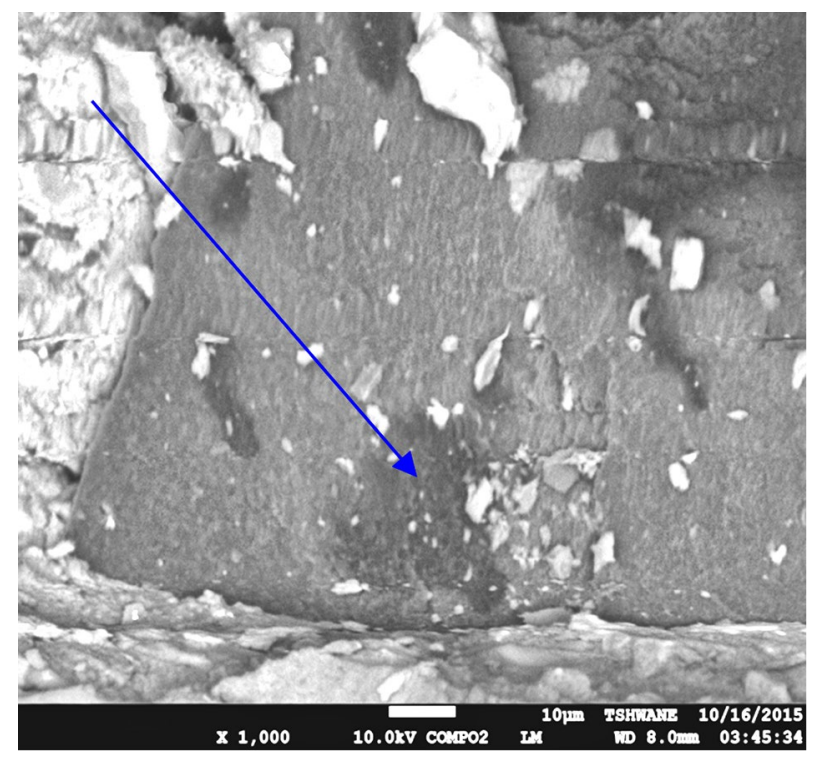

Fig.9. Sample $\mathrm{C}_{4}$

\subsection{Micrograph analysis}

Figures 8-12 showed the microstructures of all the samples, the blue arrow in the figures points to the rubber crumb in the concrete mix, the control sample $\mathrm{C}_{0}$ did not have any rubber crumb in it, large micro cracks can be visible between the interface of the rubber crumb and the concrete matrix in samples containing rubber crumb with irregular shapes. Porous capillary voids and micro cracks can be observed in the microstructure of sample $\mathrm{C}_{0}$, the cracks in samples with rubber crumbs are larger than that of the control sample, and these cracks may be shrinkage cracks caused by the evaporation of water during the curing

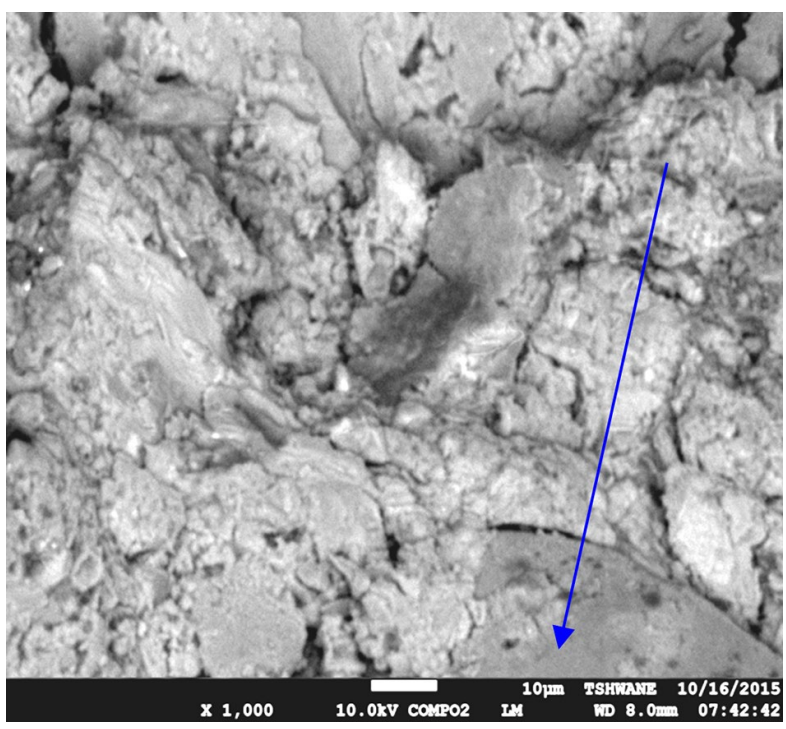

Fig. 10. Sample $\mathrm{C}_{8}$

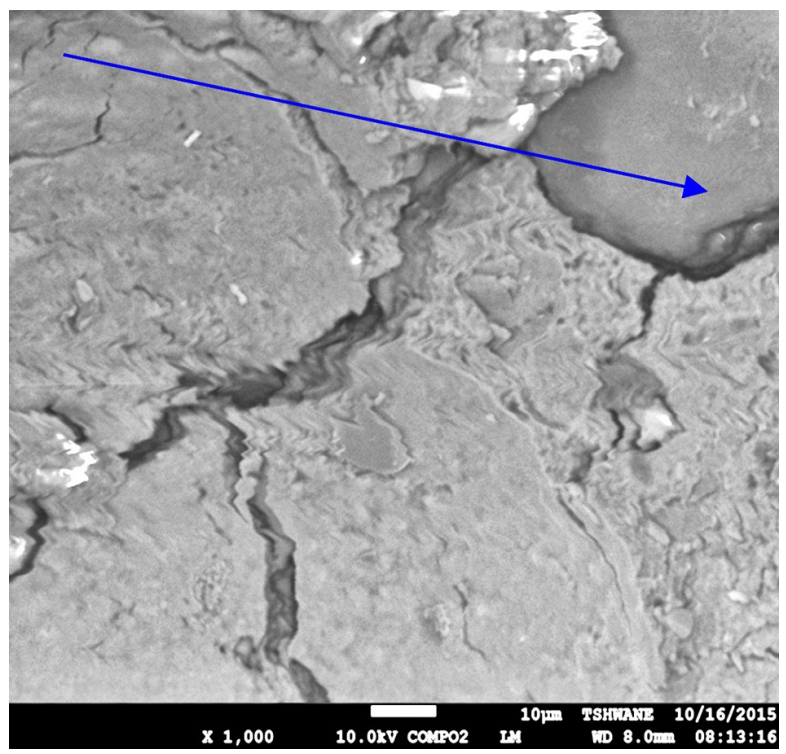

Fig. 11. Sample $\mathrm{C}_{12}$ 


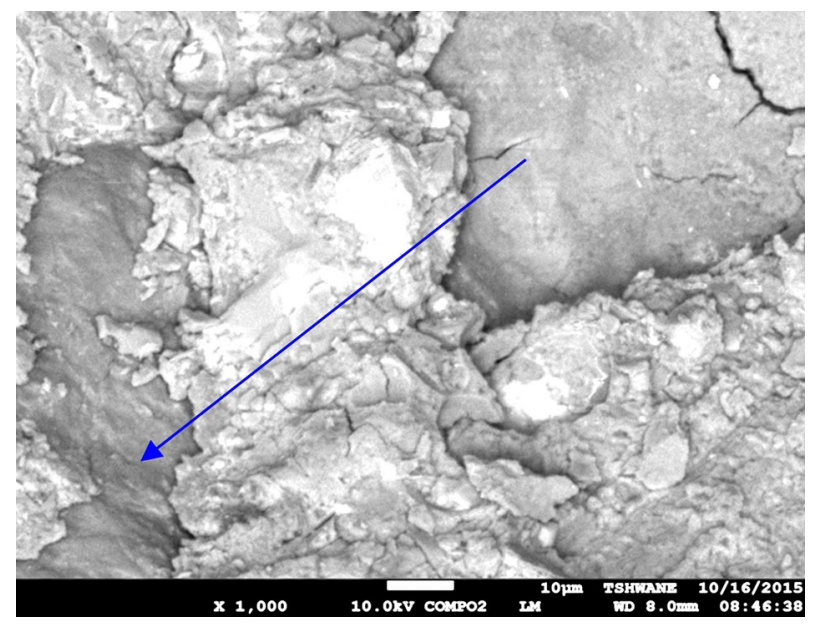

Fig.12. Sample $\mathrm{C}_{16}$

period or formed in the concrete microstructure during the compressive strength test. The capillary voids were formed from the space left behind by water after it has evaporated. These voids and cracks contributed to the reduction in the strength of concrete samples containing rubber crumb, the large micro cracks between the surface of the rubber crumbs and the concrete matrix are caused by the poor interfacial forces (Van der waals forces of attraction) between the two materials. The amount of micro cracks depends on the aggregate size and grading, cement content, water-cement ratio, degree of consolidation of fresh concrete, curing conditions, environmental humidity, and thermal history of concrete (Kumar Metha, Monteiro 2014).

\section{Conclusions}

The investigation into the effect of rubber crumb on the mechanical and chemical properties has revealed that:

1. There was a general reduction in concrete strength as more rubber crumbs were added to the concrete and these results support the findings of previous research on the mechanical properties of rubberized concrete.

2. The chemical analysis showed decrease in the amount of the very important elements like, ferrous iron (Fe), Calcium (Ca), Silicon (Si), Aluminium (Al) and Oxygen $\left(\mathrm{O}_{2}\right)$ in concrete as more rubber crumb was added to the concrete matrix, but there was increased in the amount of Carbon (C) and Sulphur (S) in the mix as more rubber crumb was added, this was mainly because the tire rubber contained a lot of carbon black and sulphur in it, and this reflected in all the rubberized samples, these two principal elements acted as impurities during the hydration process.

3. The EDX analysis revealed the dominant properties of $\mathrm{Fe}, \mathrm{Ca}$ and $\mathrm{O}_{2}$ in all the concrete samples analyzed. It can therefore be concluded that apart from the effect of rubber crumb on the mechanical properties of concrete, the chemical composition was also affected by the presence of the material in rubberized concrete.

4. The micrograph analysis showed a pattern of capillary voids and micro cracks in all the samples tested, but these cracks were more and larger in size within rubberized concrete samples than the normal concrete sample.

5. The addition of rubber crumb has no doubt has negative effect on the properties of concrete by increasing water demand, which influence the reduction in the bond between cement paste and aggregate and eventually led to the general reduction in concrete strength.

\section{References}

ASTM C496/C496M-11. 2004. Standard test method for splitting tensile strength of cylindrical concrete specimens. ASTM International, West Conshohocken PA, USA, 2004.

BS 12390 part3. 2009. Testing hardened concrete: compressive strength test of specimens. British Standard Institution, 2009.

Duarte, A. P. C.; Silva, B. A.; Silvestre, N.; de Brito, J.; Júlio, E. 2015. Mechanical characterization of rubberized concrete using an image-processing/XFEM coupled procedure, Composites Part B (78): 214-226.

http://dx.doi.org/10.1016/j.compositesb.2015.03.082

Eldin, N. N.; Senouci, A. B. 1993. Rubber-tire particles as concrete aggregate, Journal of Materials of Civil Engineering 5(4): 478-497.

http://dx.doi.org/10.1061/(ASCE)0899-1561(1993)5:4(478)

Federal Highway Administration Research and Technology (FHWA). 2006. Sample preparation for and examination with the scanning electron microscope [online]. Publication Number FHWA-HRT-04-150 [cited 17 November 2015]. Available from Internet: www.fhwa.dot.gov/publications/ research/infrastructure/pavements/pccp/04150/chapt14.cfm

Ganjian, E.; Khorami, M.; Maghsoudi, A. A. 2009. Scrap-tyrerubber replacement for aggregate and filler in concrete, Construction and Building Materials 23(5): 1828-1836. http://dx.doi.org/10.1016/j.conbuildmat.2008.09.020

Gupta, T.; Sharma, R. K.; Chaudhary, S. 2015. Impact resistance of concrete containing waste rubber fiber and silica fume, International Journal of Impact Engineering 83: 76-87. http://dx.doi.org/10.1016/j.ijimpeng.2015.05.002

Güneyisi, E.; Gesoğlu, M.; Özturan, T. 2004. Properties of rubberized concretes containing silica fume, Cement and Concrete Research 34(12): 2309-2317.

http://dx.doi.org/10.1016/j.cemconres.2004.04.005 
Karakurt, C. 2015. Microstructure properties of waste tire rubber composites: an overview, Journal of Material Cycles and Waste Management 17(3): 422-433. http://dx.doi.org/10.1007/s10163-014-0263-9

Kumar Mehta, P.; Monteiro, J. M. 2014. Concrete: microstructure, properties, and materials. Fourth ed. McGraw-Hill Professional.

SANS 5863. 2006. Compressive strength of hardened concrete. South African National Standard, 2006.

Topçu, I. B. 1995. The properties of rubberized concretes, Cement and Concrete Research 25(2): 304-310. http://dx.doi.org/10.1016/0008-8846(95)00014-3
Toutanji, H. A. 1996. The use of rubber tire particles in concrete to replace mineral aggregates, Cement Concrete Composite 18(2): 135-139. http://dx.doi.org/10.1016/0958-9465(95)00010-0

Zhang, H.; Gou, M.; Liu, X.; Guan, X. 2014. Effect of rubber particle modification on properties of rubberized concrete, Journal of Wuhan University of Technology - Materials Science 29(4): 763-768.

Zheng, L.; Sharon Huo, X.; Yuan, Y. 2008. Experimental investigation on dynamic properties of rubberized concrete, Construction and Building Materials 22(5): 939-947. http://dx.doi.org/10.1016/j.conbuildmat.2007.03.005

Joseph Olawale AKINYELE. (PhD). He is a visiting Research fellow in the department of Civil Engineering, Tshwane University of Technology, Pretoria, South Africa. He obtained his Ph.D in Civil Engineering from the University of Ibadan Nigeria. Area of interest: analysis of structures, use of yield line theory, finite element methods and civil engineering materials.

Ramadhan Wanjala SALIM. (PhD). He is a senior lecturer in the Department of Civil Engineering of the Tshwane University of Technology, Pretoria South Africa. Area of interest: theoretical and experimental studies of civil engineering structures using finite element methods.

Williams Kehinde KUPOLATI. (PhD). He is a Senior lecturer at the Tshwane University of Technology, Pretoria South Africa. area of interest: he is specialized in civil engineering materials, especially asphalts concrete, and also highway and transportation engineering analysis. 